\title{
A REPORT ON CLINICAL USES OF DROPERIDOL AND FENTANYL•
}

\author{
J. H. MORAN, M.D., D.A.(TOR.), F.R.C.P.(C), AND B. M. MARSHALL, M.D., F.R.C.P.(c) $†$
}

\section{INTRODUCTION}

THE ADMINISTRATION of combinations of droperidol and fentanyl to achieve neuroleptanalgesia has been described by a number of authors. A neuroleptic drug has been defined as a drug which will, in animal experiments, produce a cataleptic state, antagonize amphetamine, diminish sensitivity to epinephrine and norepinephrine, and antagonize apomorphine. ${ }^{1}$ To this pharmacological definition has been added the clinical observation that neuroleptic drugs produce a state of dissociation from the surroundings. ${ }^{1}$ The use of the more recently developed potent narcotic agents in combination with neuroleptic drugs has enabled performance of many surgical procedures upon fully awake or lightly anaesthetized (nitrous oxide and oxygen) patients. ${ }^{1-4}$

The general conclusions of the various authors may be summarized as follows.

1. The concept of neuroleptanalgesia has practical value to anaesthetists.

2. The combination of droperidol and fentanyl achieves the neuroleptic state with relative ease and efficiency.

3. The induction of neuroleptanalgesia is more inconvenient and time-consuming than conventional general anaesthetic techniques.

4. Neuroleptanalgesia, alone or in combination with light general anaesthesia, affords certain advantages which make the technique of benefit in many specialized situations and with certain classes of poor-risk patients.

This report outlines some of the clinical situations in which we have used the techniques, and discusses some of the benefits and disadvantages. The drugs were administered separately to allow greater flexibility in dosage than is possible with the fixed ratio provided in Innovar

\section{A. For Surgery Other Than Neurosurgery}

i. Purpose: An evaluation of the use of the neuroleptanalgesic agents in conjunction with nitrous oxide to produce general anaesthesia.

\section{ii. The Study}

a. Patient selection: Patients were selected at random but certain exceptions were made. Those undergoing emergency surgery, those with symptomatic impairment of pulmonary function, and those with coronary artery disease manifested

'Dehydrobenzpiridol R 4749 and Phentanyl R 4263, supplied by McNeil Laboratories of Canada Ltd.

fFrom the Department of Anaesthesia, University of Toronto, the Toronto General Hospital, and the Princess Margaret Hospital. 
by angina pectoris were excluded. Patients requiring muscular relaxation for the contemplated surgery were not studied.

b. Age and sex: Patients varied in age from 17 to 77 years. There were 25 females and 27 males.

c. Surgical procedures:

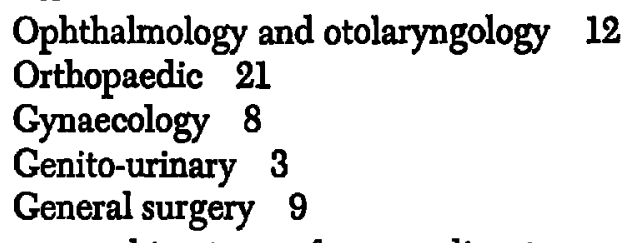

d. Method: Various combinations of premedicants were tried as well as different regimes for the administration of fentanyl. Premedication with oral pentobarbitol 100 to $200 \mathrm{mg}$. and atropine $0.6 \mathrm{mg}$. i.m. given one hour preoperatively was found to be the most satisfactory. Droperidol $5 \mathrm{mg}$. to $7.5 \mathrm{mg}$. was given in equal parts intravenously and intramuscularly 30 to 60 minutes preoperatively. Induction could be satisfactorily accomplished by simultaneous administration of nitrous oxide and oxygen (80:20 per cent), and intravenous fentanyl diluted to $0.02 \mathrm{mg}$./c.c. This technique was abandoned because of the relative ease of using a "sleep dose" of sodium thiopentone, usually 200 to $300 \mathrm{mg}$. Because of the marked respiratory depressant effects of fentanyl, maintenance of anaesthesia was found to be smoother when fentanyl was administered by continuous intravenous infusion in a concentration of $0.004 \mathrm{mg}$./c.c. in 5 per cent glucose in water. The intermittent injection of fentanyl solution ( $0.02 \mathrm{mg} / \mathrm{c.c}$.) produced wide fluctuation in respiratory rate. Nitrous oxide and oxygen (60:40 per cent) were continued throughout, and spontaneous respiration was maintained. Where intubation was required, succinylcholine in the usual dosage was given to facilitate the manoeuvre.

At the conclusion of surgery, the fentanyl infusion was stopped, 100 per cent oxygen was administered, and levallorphan $1 \mathrm{mg}$. was given intravenously. Recovery of consciousness was usually rapid and smooth, and patients were transferred conscious and without incident to the recovery room.

e. Clinical features: The method described produced satisfactory conditions for the surgical procedures listed. Respiratory depression was a constant finding, as noted by others, and a mild to moderate degree of respiratory acidosis was produced $^{2,3,5}$ (Fig. 1). Heart rate and blood pressure remained nearly constant (Fig. 2). Consciousness usually returned within five minutes, and the character of arousal was similar to that seen after physiological sleep. No patient required assistance to respiration in the postoperative period. Nearly all patients remembered the induction and did not recall it as being unpleasant. Few had any clear recollection of the operative day. They were drowsy and slept frequently, but were easily aroused.

\section{B. For Neurosurgery}

i. Patient Selection: No patient was excluded from this series because of either disease or concurrent illness. The cases, chosen to include all major neurosurgical procedures, are outlined in Table I. 


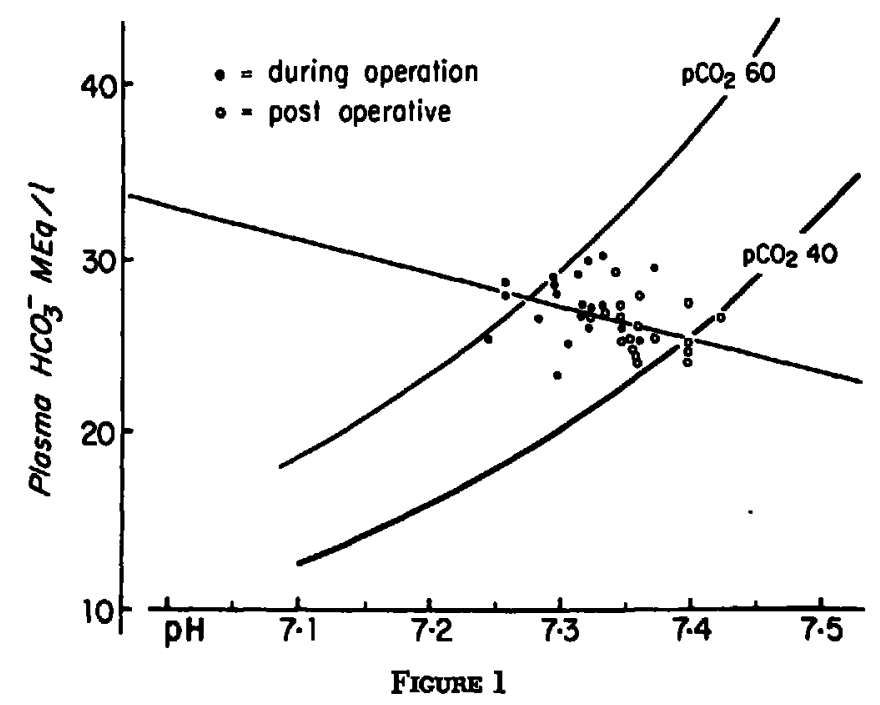

MODIFIED RADICAL MASTOIDECTOMY

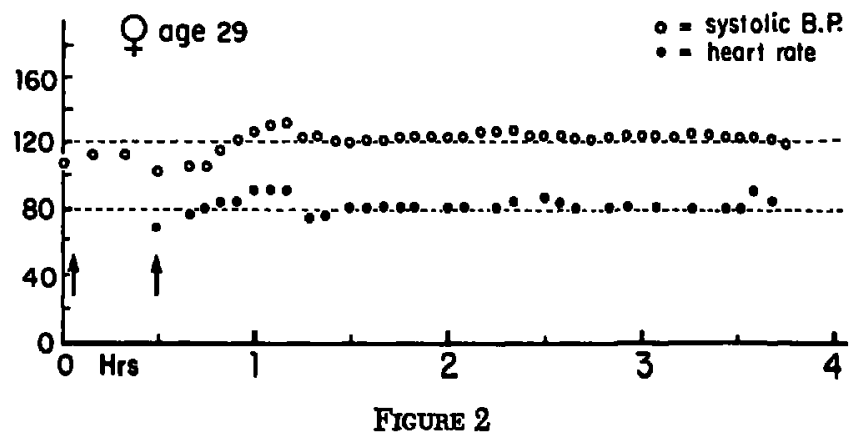

TABLE I

\begin{tabular}{lcc}
\hline \multicolumn{1}{c}{ Procedure } & No. of cases & Age (yrs.) \\
\hline Carotid endarterectomy with hypothermia to $30^{\circ} \mathrm{C}$. & 4 & $48-72$ \\
Cervical cordotomy, anterior approach & 4 & $43-65$ \\
Lumbar discotomy & 3 & $32-42$ \\
Posterior fossa craniotomy & 2 & $48-54$ \\
Fifth nerve rhizotomy (intracranial) & 2 & $33-44$ \\
Ventriculo-atrial shunt & 2 & $56-66$ \\
\hline
\end{tabular}

ii. Method: The patients were given atropine sulphate $0.4 \mathrm{mg}$. or $0.6 \mathrm{mg}$. plus droperidol $2.5 \mathrm{mg}$. or $5.0 \mathrm{mg}$. subcutaneously one hour before operation. Induction of anaesthesia with thiopentone was followed by intubation using succinylcholine for relaxation. General anaesthesia was carried on with nitrous oxide and oxygen plus halothane or methoxyflurane until the patient was positioned on the operating table. This required from five to fifteen minutes. An infusion of fentanyl $0.6 \mathrm{mg}$. in $250 \mathrm{ml}$. solution was started, and then the anaesthetic vapour was discontinued. During the initial fifteen minutes about $0.1 \mathrm{mg}$. of fentanyl per $100 \mathrm{lb}$. body weight was given. The rate of administration of the drug was about 
$0.15 \mathrm{mg}$. per $100 \mathrm{lb}$. per hour for the remainder of the procedure. The most satisfactory indication of adequate depth of anaesthesia was a reduction in respiratory rate from about twenty per minute to fourteen or sixteen per minute. The patients were breathing spontaneously except the four with carotid endarterectomy in whom hypothermia had been induced to $30^{\circ} \mathrm{C}$. At the conclusion of surgery the fentanyl infusion was discontinued and levallorphon $1.0 \mathrm{mg}$. was given if there was any indication of respiratory depression. The nitrous oxide was not discontinued until the patient was quite ready to be placed in bed.

iii. Clinical Features: In four cases the anaesthetic was not sufficient for the procedure, and halothane or methoxyflurane was added intermittently. Two cases involved cervical tractotomies, one a lumbar disc, and one a fifth nerve rhizotomy. Emergence to full orientation was extremely rapid in all cases. Two patients, one with a cervical spino-thalmic tractotomy and one with a lumbar disc, required sedation in the first thirty minutes of the postoperative period.

\section{iv. Complications}

1. Bronchospasm occurred in two patients immediately after fentanyl- $\mathrm{N}_{2} \mathrm{O}$ induction and was severe in one. Both patients were stimulated prematurely.

2. Postoperative vomiting ( 48 hours) was seen in 10 of 30 patients who received both droperidol and fentanyl.

3. Postoperative pneumonia developed in one patient following an orthopaedic procedure on the leg.

4. Symptoms of extrapyramidal disturbance occurred. Localized muscle spasm and tremor with cog-wheel rigidity were observed in two patients following intravenous droperidol. Relief was obtained with intravenous atropine.

5. Hypotension developed post-operatively in one patient. Serial electrocardiograms indicated transient myocardial ischaemia.

6. In four cases the depth of general anaesthesia was inadequate for the surgical procedure. All cases were young healthy adults who had received no barbiturate or narcotic premedication.

v. Discussion: The use of neuroleptanalgesic agents as a supplement to nitrous oxide and oxygen produced satisfactory operating conditions for the surgical procedures listed. Complications were more frequent than with the use of conventional techniques. The technique was more reliable when patients were premedicated with barbiturates and induction carried out with sodium pentothal. Remarkable constancy of blood pressure and heart rate was noted even in elderly patients subjected to prolonged periods ( 4 hours) in the sitting and prone flexed positions. Recovery of consciousness and orientation was more rapid than that observed with conventional anaesthetic agents. Administration technique is more complicated than conventional inhalation techniques.

\section{A. For Cryothalamotomy}

Neuroleptanalgesia was initially introduced at this centre to facilitate management of stereotactic surgery. ${ }^{4}$ Droperidol and fentanyl have replaced haloperidol and phenoperidine as the agents used. 
i. Purpose: The drug combination was used to produce long-acting moderate sedation plus brief almost total analgesia. Because of the nature of the surgical manipulations and subsequent testing it was impractical to attempt initial general anaesthesia followed by subsequent sedation.

ii. Patient Selection: Patients varied in age from sixteen to sixty-five years, the majority being in the sixth decade of life. The presenting symptom was primarily dyskinesia from Parkinsonism or other disease. One hundred and forty patients have undergone one hundred and ninety procedures up to December 1965.

iii. Method: The only premedication given was droperidol. The dose was $1.0 \mathrm{mg}$. per $25 \mathrm{lb}$. body weight given subcutaneously one hour preoperatively. Because of its slow and irregular action when given in this manner, droperidol is now given $1.0 \mathrm{mg}$. per $50 \mathrm{lb}$. body weight intravenously, immediately preoperatively.

The analgesic drug fentanyl is given intravenously during the initial part of the procedure in intermittent doses of $0.02 \mathrm{mg}$. to $0.06 \mathrm{mg}$. During the initial fifteen minutes $0.12 \mathrm{mg}$. per $100 \mathrm{lb}$. body weight is given. This initial dose is repeated every thirty to forty-five minutes to maintain adequate analgesia. It has been found that a respiratory rate of twelve to fourteen per minute must be achieved or analgesia is rarely adequate. A continuous infusion of fentanyl was used in some cases, at a rate of about $0.2 \mathrm{mg}$. per hour per $100 \mathrm{lb}$. body weight. It was found necessary to add supplementary doses of fentanyl during the periods of intense pain to provide adequate analgesia.

iv. Results: Sedation with droperidol was usually adequate in the doses mentioned. Overdosage usually produced increasing drowsiness and lack of co-operation. It was considered that eighty per cent of the patients had ideal sedation.

Analgesia with fentanyl was considered adequate by our standards in about eighty per cent of the cases. In these procedures a small amount of local anaesthetic was used for skin incisions, but no other medication was used for drilling burr holes, inserting ear plugs or affixing the frame. A satisfactory result was considered to have been achieved if the patient could tolerate the painful manipulations with very brief or no complaining.

v. Discussion of Clinical Features: The surgical results and the assessment of the analgesia and sedative effects of the technique have been outlined in a previous paper. 4 The substitution of droperidol and fentanyl for haloperidol and phenoperidine has resulted in one major change in technique. The neuroleptic droperidol appears to have a more prolonged action and a slower onset than haloperidol. For this reason the drug is given intravenously in smaller doses than initially.

Respiratory depression is constant, short lived, easily corrected in a conscious patient, and has never been of concern. Oxygen-saturation and blood-gas studies done during some of the procedures have never yielded results in the abnormal range.

Peripheral cyanosis does occur in some patients. Hypotension was noted in two patients. On both occasions it was corrected by placing the patient in the headdown position.

The tremor or rigidity associated with the dyskinesia was not altered in these 
patients. Muscular rigidity was not noted to be initiated by either drug. The patients were drowsy in the postoperative period, and the following day few remembered much of the procedure.

In retrospect, there was no apparent way of predicting whether or not the technique was going to be successful. The younger, more alert, and more active patients may predominate in the unsuccessful group, but this has not as yet been of statistical significance.

\section{B. For Radiotherapy}

i. Purpose: Analgesia was required for the relief of pain produced by a pneumatic tourniquet applied proximal to malignant neoplasms of the lower limb. The tourniquet was in place for periods of forty-five to ninety minutes. Tissue anoxia produced by occlusion of arterial blood supply allows the administration of relatively high doses of radiation to the diseased area without producing the damage to skin which would otherwise be expected. ${ }^{6,7}$

ii. Patient Selection: Eight patients, five males and three females, ranging in age from fourteen to sixty-four years, were treated. All had histologically proven sarcomatous neoplasms of the lower limb. Three patients had radiologic evidence of pulmonary metastases and received palliative therapy requiring from one to four radiation treatments. Five patients without evidence of metastatic disease each received a total of twelve treatments given twice weekly, during which a total of $12,000 \mathrm{R}$ was administered to the diseased area. In addition three of the latter group were given $1,500 \mathrm{R}$ to the chest as prophylaxis.

iii. Method: The nature of the therapy required:

a. The relief of pain produced by the tourniquet.

b. Frequent (bi-weekly) treatments.

c. Control of the patient isolated in the radiotherapy room. It was felt that neuroleptanalgesia could be used to fulfil the above requirements.

Patients were premedicated with pentobarbital sodium 100 to $200 \mathrm{mg}$. given orally ninety minutes before treatment. Droperidol $5.0 \mathrm{mg}$. to $7.5 \mathrm{mg}$. was administered in equal parts intramuscularly and intravenously sixty minutes before treatment. Immediately prior to stripping the affected limb with an Esmark bandage and application of a pneumatic tourniquet, fentanyl was given intravenously in a concentration of $0.02 \mathrm{mg}$./c.c. in an amount sufficient to slow the respiratory rate to between eight and twelve per minute. This amount of respiratory depression was found to coincide with a satisfactory level of analgesia. Reinforcing doses equal to one quarter of the initial doses were given as necessary each fifteen to twenty minutes as indicated by restlessness, complaint of pain, or increasing respiratory rate. Levallorphan $1 \mathrm{mg}$. was given intravenously at the conclusion of each treatment.

iv. Results: The method described was found to be satisfactory. The dosage of fentanyl required had no apparent constant relationship to the age, sex, weight, or physical state of the patient. It varied greatly both from patient to patient ( 0.14 to $1 \mathrm{mg}$.) and in individual patients on different days $(0.15$ to $0.80 \mathrm{mg}$.). It was noted that when the patient was apprehensive, the requirement of fentanyl was high. 
Tests of liver function (B.S.P. Vandenberg, C.C.F., alkaline phosphatase) were carried out on the five patients who received twelve treatments, at the conclusion of the series. No patient showed significant impairment of liver function as indicated by the above tests. No changes occurred in haemoglobin concentration, white blood count, platelet count, or urinalysis.

Patient acceptance of the method was good. Blood pressure tended to rise 20 to $30 \mathrm{~mm}$. Hg from pretreatment levels, and heart rate also increased slightly.

\section{v. Complications}

a. Respiratory depression occurred in all patients. On two occasions respiratory arrest occurred and short periods of artificial ventilation were required.

b. Muscle fasiculation or shivering of mild degree were observed in three patients.

c. Three patients vomited more than once in the post-treatment period. This is of doubtful significance because of the concurrent radiation therapy.

d. A diffuse patchy erythema involving mainly the head, neck, and trunk occurred with each treatment in four of the five patients treated twelve times. This faded in a few hours and the skin returned to normal appearance.

vi. Conclusions: This method produced satisfactory conditions for the radiation therapy described. Complications, when they occurred, were minor. Patients given repeated doses of fentanyl and droperidol over a six-week period tolerated them well.

\section{III}

\section{A. Miscellaneous Uses}

i. As a Preoperative Sedative: The neuroleptic drugs have been used as preoperative sedation for procedures done under local and general anaesthesia.

a. Purpose: To evaluate the sedative properties of the neuroleptic drugs.

b. Selection: The patients selected were those undergoing investigative or relatively short operative procedures. No patient was excluded because of physical status.

c. Method: Droperidol was given subcutaneously one hour preoperatively in a dose of $1.0 \mathrm{mg}$. per $25 \mathrm{lb}$. body weight. Very elderly or debilatated patients were given half the dosage. The patients undergoing investigative procedures had local anaesthetic injected for skin wheals when necessary. Patients undergoing general surgery were also given atropine preoperatively. The general anaesthesia consisted of thiopentone induction followed by maintenance with nitrous oxide and oxygen plus halothane or methoxyflurane. All patients were breathing spontaneously, and most had endotracheal intubation.

d. Results: Observation recorded from twenty investigative and twenty operative procedures are recorded in Table II.

e. Discussion: Apprehension and/or lack of co-operation were noted in many of the cases. Curiously, some difficulty was found in re-establishing spontaneous respiration following intubation in general anaesthesia. This was troublesome in many cases, since it became necessary to have the patient awake to the point of coughing and moving before spontaneous respiration resumed. As a result, it is 
TABLE II

Reactions to 20 Operative and 20 investigative Procedures

\begin{tabular}{lccccc}
\hline \hline & $\begin{array}{c}\text { Adequate } \\
\text { sedation }\end{array}$ & Emesis & $\begin{array}{c}\text { Cardiovascular } \\
\text { depression }\end{array}$ & $\begin{array}{c}\text { Respiratory } \\
\text { depression }\end{array}$ \\
\hline $\begin{array}{l}\text { Investigative procedures } \\
\text { Operative procedures }\end{array}$ & $\mathbf{1 4}$ & $\mathbf{0}$ & 0 & 0 \\
\hline
\end{tabular}

now the practice to give droperidol after induction of general anaesthesia to take advantage of its marked effectiveness as an anti-emetic and postoperative sedative. Because of the apprehension observed, and because of the notable absence of sedative effect, droperidol is not considered an ideal drug for use as a routine sedative for investigative procedures. Since there had been no evidence of respiratory or cardiovascular depression in patients who were to remain awake, the drug was given to patients with intracranial lesions in whom further central nervous system depression was perhaps dangerous. In these instances it was considered that the patient became more manageable and that the procedure was markedly facilitated.

ii. To Produce Respiratory Depression and Facilitate Artificial Ventilation: In order to depress respiratory drive and facilitate the institution of intermittent positive pressure ventilation, an attempt was made to use fentanyl as an alternative to curarization in ten patients with respiratory failure secondary to pulmonary disease and in patients with pulmonary oedema due to cardiac failure. The results were disappointing in both cases, and doses of fentanyl of $1 \mathrm{mg}$. were ineffective.

\section{SUMMARY}

The drugs introduced from Europe to produce neuroleptanalgesia have been investigated, separately and together, in an attempt to determine whether they have sufficient merit to make them necessary to, or desirable in, the anaesthetist's armamentarium. Our study varies from most others which have been reported in that all our patients were breathing spontaneously, and in that the neuroleptic and analgesic drugs were given separately rather than in a fixed combination.

We have found the drugs both separately and in combination to have certain benefits and certain disadvantages, as outlined above. Our conclusions based on this clinical appraisal are:

1. Induction and maintenance of neuroleptanalgesia plus light general anaesthesia is moderately complicated.

2. Intramuscular administration of droperidol gives less consistent results than intravenous administration.

3. Respiratory depression is frequent, but is easy to control.

4. Cardiovascular function is extremely stable with this form of anaesthesia.

5. Bronchospasm and/or muscular rigidity may occur during the course of anaesthesia.

6. The postoperative course is notable for its apparent lack of pain and the prolonged tranquility of the patient. 
7. Droperidol alone has marked anti-emetic properties, but slight hypnotic properties.

8. Neuroleptanalgesia as a supplement to nitrous oxide is not sufficient to provide adequate anaesthetic coverage for surgical procedures in some patients without the addition of further narcosis or of another anaesthetic agent.

The technique of neuroleptanalgesia (without added general anaesthetic) or neuroleptanaesthesia (with added general anaesthetic) should be considered in the following situations.

1. Investigative or surgical procedures where patient co-operation is necessary.

2. Procedures where cardiovascular stability may be jeopardized due to movement or position of patient.

3. Procedures where patient disease or anaesthetic toxicity contraindicates conventional anaesthetic techniques.

4. Procedures in which postoperative tranquility without depression of the cardiovascular system and with or without depression of the respiratory system is desired.

5. Procedures in which immediate postoperative alertness is desired.

\section{Résumé}

Nous donnons, dans ce rapport, une évaluation des usages cliniques du droperidol, médicament neuroleptique et du fentanyl, narcotique synthétique. Nous avons employé le droperidol seul comme sédatif avant des opérations pour diagnostic et aussi avant l'anesthésie générale. Nous avons employé ensemble le dropéridol et le fentanyl, mais non dans une proportion précise, aussi bien pour neuroleptanalgésie (sans l'addition d'anesthésique général) que pour neuroleptanalgésie (avec l'addition d'anesthésie générale). Nous discutons les problèmes d'administration, les avantages et les désavantages et les complications à la suite de l'usage de ces médicaments.

Brièvement, nous en venons à la conclusion que bien que la technique d'administration présente des problèmes, ces derniers peuvent être facilement résolus. Cette technique offre des possibilités et nous sommes d'avis qu'il se présente des situations cliniques où cette technique devrait être envisagée comme la plus indiquée pour résoudre le problème.

\section{ACKNOWLEDGMENTS}

The authors wish to express their appreciation to Dr. William Allt and the Radiotherapy Department of the Princess Margaret Hospital, Toronto, for their interest and co-operation.

\section{REFERENCES}

1. Smephern, N. W. Editor. The Application of Neuroleptanalgesia in Anaesthetic and other Practice. Proceedings of the First British Symposium, 1st ed., Oxford: Pergamon Press (1965).

2. Warken, R. \& McINTYRe, Jomn W. Clinical Experiences with a Combination of Fentanyl and Droperidol. Canad. Anaesth. Soc. J. 12: 361 (1965). 
3. Spozrer, W. E. \& Chan, W. S. Innovar in Surgical Anaesthesia. Canad. Anaesth. Soc. J. 12: 622 (1965).

4. Tasken, R. R. \& Marshadx, B. M. Analgesics for Surgical Procedures Performed in Conscious Patients. Canad. Anaesth. Soc. J. 12: 29 (1965).

5. Dobzin, Allan B.; Isrnes, Jacob S.; \& Byles, Pejer $\mathrm{H}$. Innovan- $\mathrm{N}_{2} \mathrm{O}$ Anaesthesia in Normal Men: Effect on Respiration, Circulatory Dynamics, Liver Function, Metabolic Functions, Acid-Base Balance, and Psychic Responses. Canad. Anaesth. Soc. J. 11: 41 (1964).

6. SUtr, H.; Fuetcher; TAYlon; \& White. Response of Anoxic Human Tissue: Normal and Malignant: Report of Work in Progress. M. D. Anderson Institute (1964).

7. Déray, R.; Pelletien, J.; JacQues, A.; Clavet, M.; \& Houde, J. J. Metabolic Changes Induced in the Limb during Tourniquet Ischaemia. Canad. Anaesth. Soc. J. 12: 367 (1965). 